\section{Research Co-ordination Committee}

An account of the work carried out by the Research Co-ordination Committee during the past year was given at a meeting of the Group held in Cambridge on August 22. The work included (1) a list of essential statistics, on which the views of bodies utilizing statistical data (Political and Economic Planning, Engineers' Study Group, New Fabian Research Bureau), the Institute of Statistics and several leading statisticians have been obtained; (2) co-ordination of work on South Wales problems including a résumé of industrial proposals, bibliography on South Wales, report on land improvement, and on family budgets of employed and unemployed workers ; (3) information on numerous societies and sources of information, which it is hoped will be published in the form of a directory of associations. The Research Co-ordination Committee has also been active in bringing together editors of scientific and other periodicals to consider co-ordinating publications and has gathered material which is to be put before the new Division of the Social Relations of Science of the British Association.

\section{Safeguarding Unpublished Research}

DURING the recent period of uncertainty in international relations, the Research Co-ordination Committee approached several organizations having valuable unpublished data with the view of securing co-operation for their safety in case of war. The microfilm technique of duplication was considered, since it is relatively inexpensive (about $0 \cdot 1 d$. per page) when the necessary apparatus, which can be hired for a minimum period of one year, is available. This could be arranged if a sufficient number of bodies co-operate. The response has been satisfactory, and others interested should communicate with the Hon. Secretary, Research Co-ordination Committee, 35 Gordon Square, London, W.C.1.

\section{Memorandum on Smallpox}

DURING the last three years, Great Britain has enjoyed comparative freedom from smallpox, and the Ministry of Health has therefore considered it appropriate to issue a memorandum in order to direct the attention of local authorities to the possibility which now exists of limiting the spread of smallpox by prompt and vigorous action as soon as it is reported to have appeared (Memo. 215 (Med.). London : H.M. Stationery Office. 2d.). The memorandum contains an account of the incidence of, and mortality from, smallpox in England and Wales since 1901, and a summary of the procedure which should be adopted should the disease appear in a district.

\section{Suggested Science Museum for Cambridge}

A LARGE exhibition of historic scientific instruments and specimens was arranged under the auspices of the Cambridge Philosophical Society for the meeting of the British Association last August. It was most gratifying to see the long series of instruments associated with the great masters of the Cavendish Laboratory-with Wollaston, Clerk Maxwell, J. J.
Thomson, Rayleigh and Rutherford-but the older periods were also well illustrated by loans from the colleges. At the final meeting of the General Committee in Cambridge, it was resolved "that an expression of hope that the scheme for a permanent exhibition of historic seientific instruments in Cambridge would be brought to fruition, should be communicated to the University authorities", and this has been done.

\section{Electrified Omnibuses}

Mr. A. E. Wrseman, 21 Hanbury Road, Acton, London, W.3, writes stating that on boarding an omnibus recently, he felt a distinct electric shock on grasping the metal handrail, with one foot on the step and the other on the pavement. The effect was also observed by others, particularly on 'crisp' mornings. He suggests that the electricity may be caused by the friction of the tyres on the ground, which incidentally insulate the body of the bus. It is of interest to note that this effect was described in a letter in NATURE of June 29, 1929, p. 981, by Sir Charles Boys, who observed it on a hot dry day and ascribed it to the scuffling of the tyres on the polished asphalt.

\section{A Naked-Eye Sunspot}

A GIANT sunspot, easily visible to the naked eye, is crossing the sun's disk in latitude $17^{\circ}$ north from October 5 until 18, the time of central meridian passage being October $11 \cdot 9$. The area of this spot on October 6, corrected for foreshortening, was nearly 2,500 millionths of the sun's hemisphere, and on October 8 its area measured 2,800 millionths, the measurements being made at Greenwich Observatory. The spot on the latter date extended in solar longitude for about 125,000 miles. Sunspots as large as this one are usually associated with terrestrial magnetic disturbances commencing about one day after the time of central meridian passage. On October 7, a small magnetic storm was recorded at the Greenwich magnetic observatory at Abinger, the disturbance reaching a maximum between $16^{\mathrm{h}}$ and $20^{\mathrm{h}}$ U.T. The ranges of the magnetic elements were : in declination $51^{\prime}$; in horizontal force $200 \gamma$; and in vertical force $260 \gamma$. It seems uncertain, however, whether this magnetic disturbance can be linked to the big sunspot; the most probable time of one related to the disturbed area of the sun containing this sunspot would be about October 12-13.

\section{Colonial Service Appointments}

THE following appointments in the Colonial Service have recently been made: W. D. L. Corby, agricultural officer, Nigeria; T. N. Greeves, agricultural officer, Nigeria; D. G. Jones, agricultural officer, Malaya ; H. T. Measurs, agricultural officer, Kenya ; R. J. S. Waddington, inspector of mines, Nigeria; D. Luke, veterinary officer, Uganda ; L. D. Branch, inspector of plants and produce, Gold Coast ; C. L. Crosse, sleeping sickness control officer, Nigeria; J. H. C. Hicks, sleeping sickness control officer, Nigeria; R. Patterson, inspector of plants and 